\title{
50 YEARS AND STILL GOING!
}

\author{
Prof. Cristina Mandravel \\ Department of Physical Chemistry, Bucharest University, Bucharest,4-12BlvRegina \\ Elisabeta,030018, Romania.chrism@gw-chimie.math.unibuc.ro
}

\begin{abstract}
Magnetic susceptibility is an important property of substances.In the first part of this paper is exposed the hystory of realization, development and use of the first installation devoted for magnetic susceptibility determinations at Physical Chemistry Department of Bucharest University.Professor I.G.Murgulescu gived to lecturer V.Mincu the subject: Determination of magnetic susceptibility for the Ph.D.Thesis in 1964, when was enrolled for graduate studies in the system "frequenceless".V.Mincu opted for the all used then Gouy balance based method and he realized his installation in 1967in the research laboratory for IRSpectrometry and Magnetochemistry of our department-located in E-215 of central building of Bucharest University.His installation placed into a wall's niche and on adiacent table (with $1.5 \mathrm{~m} * 1.5 \mathrm{~m}$ dimensions) was very voluminous.Until his premature death in 1986, V.Mincu worked with dedication on this installation, mentored many graduate students to measure magnetic susceptibility, colabored with different researchers in inorganic and physical chemistry to calculate on this basis electronic and geometric structure of different compounds, published four ISI papers and obtained two national patents.Between 1987-1998 under volunteer coordination of lecturer eng.L.Radulescu graduate students M.Nanu, D.Licsandru made theyr apprentice on the revized installation and obtained consistent data which were presented at different conferences.Between1998-2002 was effected consolidation of central building of Bucharest University.Before to move our laboratory equipment graduate student I.Iosub plotted a detailed schema of the installation, which was then desmembered.Only electromagnet rested in the niche, covered with a special case.We asked to civil engineer to keep and extend the niche.In 2003 graduate student A.Soare has again revized installation which was all integrated in the niche, elabored new work instructions, executed calibration.He published all these data with some proposals for future improvement of installation (see: http: //www.gwchimie.math.unibuc.ro/AUB) At this instalation can be effected studies of the paramagnetic susceptibility dependence of temperature.for solid substances.In 2015 the space of our research laboratory was transferred to the didactic laboratory of Inorganic Chemistry because of consolidation work needed, at this time, for the Chemistry faculty building from 90 Panduri Avenue.Then I reccomended a wood-door closing of the niche as protection measure for the installation during the transfer operations. We moved only DOR and FT-IR spectrometers in a didactic laboratory of Physical Chemistry, where work smaller groups of students.Thus, this many revized, robust and laborious installation for magnetic susceptibility determinations can be reopened in the new laboratory of Inorganic Chemistry for measurements and demonstrations.This installation still going!In the second part of this paper after a selective search of literature on magnetic susceptibility determinations (paper contain only 21 references) is characterized the actual stage of this domain.On this basis, in the paper conclusions a comparative analysis of the performance characteristic, for both the methods and commercial instruments, now used in such measurements, is done.
\end{abstract}

Keywords: Chemistry, magnetic susceptibility, magnetic field strength, magnetic moment per unit of volume, diamagnetism, paramagnetism, ferromagnetism, type of installtions for measurements of magnetic susceptibility.

\section{Introduction}

Substances introduced in a magnetic field, with the strength $\mathbf{H}$, (expressed in SI units in $\mathrm{A} / \mathrm{m})$ are diamagnetic or paramagnetic .Its 
behavior is described by general equation:

$$
\mathbf{J}=\boldsymbol{\chi} \mathbf{H}
$$

where: $\mathbf{J}$-formed magnetic moment per unit of volume $[\mathrm{A} / \mathrm{m}] ; \quad \boldsymbol{\chi}$-magnetic susceptibility, which is dimensionless.

Magnetic moments are not measured directly. Instead, they are calculated from measured magneticsusceptibilities. From mul- tiple measurements results that diamagnetic substances have negative $\chi$ values comprised between $-10^{-5}$ and $-10^{-6}$.In this category can be included all organic substances and nonme-tals with exception of oxygen and sulphur[1].All the elec- trons, contained within atoms or molecules of these substan- ces, are paired. The paramagnetic substances have pozitive $\chi$ values with the same order, but these are temperature dependent, as Pierre Langevin established in $\mathbf{1 9 0 5}$ [2]. In this cate- gory are included: metals, organic radicals, oxygen and sulphur. A subcategory of paramagnetic substances having big $\chi$ values $\left(10^{-3}\right)$ includes the metals from $\mathrm{Fe}$ group (ferromag-netic). In the intimate electronic structure of these substances exists many unpaired electrons. From these facts results that magne- tic susceptibility measurements can lead to a conclu-sive electronic structure of the studied compounds!

The first experimental work on magnetic susceptibility are reported by $\mathrm{R}$ Shida in 1883[3]. Until 1980's Gouybalance method for these measurements was widely used [4].

\section{On the installation}

In 1964 Acad.Professor I.G. Murgulescu, chief of Physical Chemistry Department from Bucharest University, gived to lecturer Valentin Mincu the subject: Determinations ofmag-netic susceptibility for the Ph.D Thesis. This year was the cen-tenial year of our university! V.Mincu (chief of $\mathbf{1 9 5 8}$ Class of Faculty of Chemistry) was enrolled for doctoral studies in the system "frequenceless." After he sustained the exams and searched the literature opted for the all used then Gouy balance-based method and in 1967 he realized his installation. (those principle schema is done in "Figure.1"[5]) in the research laboratory for IRSpectrometry and Magnetochemistry of our departmentlocated in room E-215 in the central building of Bucharest University.

In conformity with "Figure 1" the two electromagnets (1) create a homogenous magnetic field to $\mathbf{z}$ direction (this means that $\mathbf{d H} / \mathbf{d z}=$ constant) where is introduced the quartz rod (2) of a torsional balance (3). On the balance pan, attached to thequartz rod, the sample of substance is adding and onto the other pan (4) the weights are adding. About $10 \mathrm{mg}$ of substances is weight in default of magnetic field. When magnetic field is applied, we will observe a lost of balance equilibrium: a paramagnetic (or ferromagnetic) sub-stance will apparently be weightier, a diamagnetic substance will apparently be lighter. Thus, we may deduce, instantly, the type of the substance susceptibility!

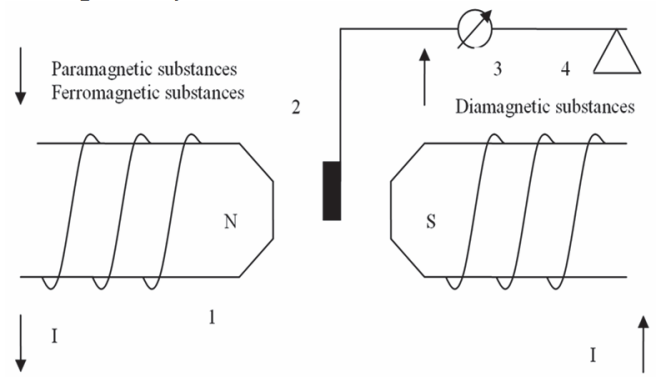

Figure 1. Principle schema of installation for magnetic susceptibility determination [5]

Begining with 1968 year, under V. Mincu ferm coordination on that installation were affected measurements by a serie of graduate students and some interested researchers. Working in the same laboratory, in domain of IR spectrometry, I re- member some students: Marius Andruh, Eftimie Nesfantu, Oana Carp, Rodica Ion, Marin Micut-today renomed chemists!

In 1977, during earthquake a part of the spool (reel) wire of the magnet was compromised, but our laboratory not need many reparations in the time of that consolidation work. The magnetic susceptibility was calculated with equation:

$$
\chi=\Delta \mathbf{m} / \mathbf{m} . \mathbf{H} . \mathbf{d H} / \mathbf{d z}
$$


where: $\Delta \mathbf{m}$-is the mass variation of the checking substance; $\mathbf{g}=9.8 \mathrm{~m} / \mathrm{s}^{2}$ is gravitational acceleration; $\mathbf{m}$-is the weight of the checking substance (order of $\sim 30 \mathrm{mg}$ ). Factor $\mathbf{H . d H} / \mathbf{d z}$-is calculated from previous measurements using a standard substnce with $\chi$ known.

V. Mincu (1936-1986) was open to collaboration with others specialists in inorganic and physical chemistry, exploiting mass measurements in different environments. $\mathrm{He}$ obtained two national patents and published four ISI papers before his premature death. In some cases he studied variation of $\chi$ with temperature[6-8].

Between 1987-1998 under volunteer coordination of lec- turer eng. Liviu Radulescu (1929-2015) the graduate students Mihai Nanu, Dumitru Licsandru made their apprentice on the revized installation and obtained consistent data, which were presented at different conferences [9]. These facts concured to obtain a research grant from Romanian Academy, from which we ammeliorated our laboratory equipment.

But, between 1998-2002 was affected the second consoli- dation of central building of Bucharest University, a complex operation, because it is a historic monument! We have not evacuated from building: only for a time, we were mouved (mans, furniture and equipment.) from a part of central couloir on the other.and back! Before to move our laboratory equip- ment to permit the consolidation works, the graduate student Ion Iosub made a poster with detailed schema of the installa-tion. (As note of humor: the poster received a precious frame valued from a portret of "much loved chief", mandatory in any didactic space before1989!). After this, installation (then placed in the niche and on adiacent table with $1.5 \mathrm{~m} * 1.5 \mathrm{~m}$ di- mensions) was desmembered and only electromagnet (for it a special case was made) rested in the niche.

In 2003 Aurel Soare, working for his disertation in master degree in Physical Chemistry \& Radiochemistry, has revised installation. This was integrated in the niche, now with nearly doubled volume. (see Figure.2) $\mathrm{He}$ also elabored new work instructions and executed the calibration.
Belong of avantage of the compactisation, in comparison with initial installa-tion, this new arrangement favors the stability and reproductibility of measurements, which, truly, are laborious.

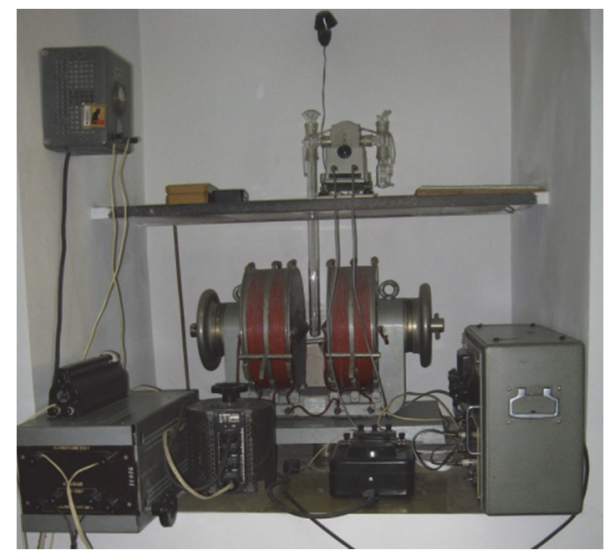

Figure 2. General view of new designed installation [10]

Because the consolidation of central university building has been developed as a "building inside of the externall walls" we asked to constructor to keep and extend the intraspace into the wall (the niche) The final dimensions of the niche are: $2.1 \mathrm{~m}$ height, $1.2 \mathrm{~m}$ width and $1.1 \mathrm{~m}$ depth. So, after consolidation, for the rest of our laboratory the work space was smaller than before, but the space for this installation increased and all is integrated in the niche!

When installation was reassembled, all electrical devices were verified and all the electrical contacts were cleaned. The electromagnet, visible in "Figure.2", is made of two conical polar pieces The distance between these may be varied with an accuracy of $0.5 \mathrm{~mm}$. The magnetic field is yield with the aid of four copper reels, grouped in pairs. These reels, which are serial interlinken, have a resistance of $7 \Omega$ and the terminal voltage is $125 \mathrm{~V}$ for a maximum current of $18 \mathrm{~A}$ (but, as been already explained, after 1977 earth quake accident, maximum ampe-rage, suported now by the installation, can be increased only to 8A) .For the calibration of the installation was used as stan-dard substance Mohr salt and for checking 
substance pota- sium ferricianide, Merck, p.a.

For the more laborious experiments, related with the study of the paramagnetic susceptibility dependence of temperatu-re, the quartz tube, visible in "Figure.2", is substituted with a double walls tube for circulation of the refrigerent liquid. The routine determinationns, related with weighting operations, have to begin only after achievement of the thermal equili-brium state!

In 2008 graduate student Aurel Soare published all these data with some proposals for upgrading of the installation [10] (see: http: //gw-chimie.math. unibuc.ro/AUB). He continued to work for his doctoral thesis in domain of theIR spectrometry, applied for searching of the corrosion products, which he sustained in 2009.

In 2015 the space of our research laboratory was transfered to the didactic laboratory of Inorganic Chemistry because of consolidation works needed, at this time, for the Chemistry faculty building from 90 Panduri Avenue.Then, I recommen-ded a wood-door closing of the niche, as protection measure for installation, during of the transfer works. We moved only DOR and FT-IR spectrometers in a didactic laboratory of Physical Chemistry, where works smaller groups of students. Thus, revized installation for magnetic susceptibility determi-nations can be re-opened for measurements and demonstra- tions in the new laboratory of Inorganic Chemistry (the same room E-215)!

\section{3}

- By the time, I searched literature in domain of magnetic susceptibility data.It is obvious a big number of papers publi-shed in Journal of Chemical Education This fact is, perhaps, in causal relation with idea that magnetic susceptibility mea-surements can lead to a conclusive structure of the studied compounds in the General Chemistry laboratory..I find the works of professor D.F.Evans from Imperial College of London.In 1959 he published a paper[11] on the possiblity to determine $\chi$ of the ferromagnetic compounds in solutions from their HNMR spectra-a powerful, but costly tool!And now the NMR spectrometers are disponible only in some central research institutions in our country and our students learn their use, in general, by problematisation [12]!

In 1974 Evans proposed a new type of balance. In the Evansbalan-ce [13] "the sample stays still and a small magnet is attracted (or repelled) by the sample. The magnet is balanced on a fine wire (actually a flat type) which twist in response to the force acting on the magnet.This is what makes the instrument sensitive and fragile, despite its chunky appearence-please treat it gently!"Sherwood Scientific Instruments deve-loped on this basis a portable instrument with a digital readout, that permits a quick reading with sensitivity matching traditional apparatus .It can be used for solids, liquids and solutions. The cost of the instrument is $\sim 8500 \$$, but the sample tubes (needed in big number in the case of didactic experien-ces leaded with numerous students in General Chemistry laboratory) are also costly: $\$ 20$ for a sample tube[14]. With the Sherwood instrument [13] magnetic susceptiblity for solid substances is done by equation:

$$
\mathbf{X}=[\mathbf{L C} \Delta \mathbf{R}] /\left(\mathbf{m} .10^{9}\right)
$$

where: L-sample length (cm); m-sample mass (g); C-balance calibration constant (printed on the back of the instrument); $\Delta \mathbf{R}$-is the difference between the reading for the digital display with sample in tube and reading, for the same digital display, with empty tube. Is recommended to verrify calibration con-stant periodicaly with a standard substance.

In 1968 two japanese researchers gived a new method for the determination of $\chi$ foraqueous solutions of the transitional group elements chlorides by measuring their time of flow through the capillary of a viscosimeter in presence of an ex-ternal heterogenous magnetic field [15]. Their data have an accuracy of $0.5 \%$ of true magnetic susceptibility. It is necce-sary to mention that firm Holmarc created instruments in which magnetic field is measured with a digital gaussmeter for both Gouy (model HG-EDEM-08: $3117 \$$ ) and viscosi-meter (model HQ-ED-EM-07: 1900\$) methods.In "Figure.3" is done aspect of model HG-ED-EM-08 Gouy method apparatus for study of solide samples.It is more compact than our installation, presented in "Figure.2", easier to handle, but it cannot be used for study of 
temperature dependence of the paramagnetic substances, as results from study of the firm's prospect.

More recently, JFSchenk published a work [16]. cited in 640 others papers, on the role of magnetic susceptibility in magnetic rezonance imaging (MRI). He demonstrates that quantitative use of susceptibility data is important to MR-guided surgery. $\mathrm{He}$ recommended uniform use of SI units for magnetic susceptibility and related quantities to achieve consistency. An updated tabulation of $\chi$ values has been given in [17].

Using the Holmarc's robust instruments [18] resear-chers from U.S. Geological Survey studied magnetic suscep-tibility and density for plutonic and metamorfic rocks of the Glacier Peak Wildernes and vicinity, Northen Cascades, Washington [19].

Another modern method [20] using MRI/NMR techniques measures the magnetic field distorsion around a sample immersed in water inside a MRscanner.This method is heig-hly accurate for diamagnetic materials with susceptibility similar to water.

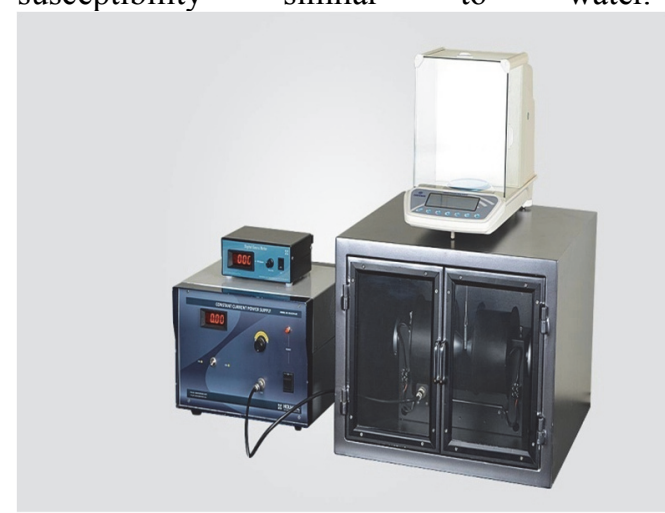

Figure 3. General view of Holmarc's magnetic susceptybility Gouy method apparatus model HG-ED-EM-08. [18]

Now, in the studies on magnetic properties of nano and biomaterials SQUID (superconductivity quantum interference devices) magnetometers are used [21]. But, these instruments work on another priciple. The magnetometer is "an instrument that measure magnetiza-tion of magnetic material or direction strength, or relative change of a magnetic field at a particular location".
SQUID type of magnetometer can be used to measure the magnetic fields produced by laboratory samples, also for brain activity (magnetoencephalography) or hearth activity (magnetocardio-graphy). But geophysical surveys use SQUID-magnetometer from time to time, because of complicated logistic of cooling needed for their function. SQUIDmagnetometer are noise sensitive and for this reason impractical in laboratory in high DC magnetic fields. Commercial SQUID magnetometers, cooled with liquid helium or liquid nitrogen to operate, are available for temperatures between $300 \mathrm{~K}-400 \mathrm{~K}$ and magnetic fields up to $7 \mathrm{~T}$.

\section{Conclusions}

I. In this work are described the significants moments in realisation (in 1967), developmentand use of the installation devoted to magnetic susceptibilty determinations, using Gouybalance method, at Department of Physical Chemistry.from Bucharest University.It have 50 years, work with it is labo-rious, but still going! It permit study of dependence on tempe-rature for magnetic susceptibility of paramagnetic solid subs-tances.

II. From a selective literature search we evidenced other methods used for magnetic susceptibility determinations:

a) For the ferromagnetic compounds in solution: a power-ful, but costly method based on the study ofH-NMR spectra and one simple, but also laborious, using an viscosimeter pla-ced in magnetic field.

b) For solid, liquids and solutions: a very used method today, based on Evans balance, from which was developed a commercial portable instrument, not so costly, but because of restrained space in region of probe, it no permit study of the temperature dependence for magnetic susceptibility of the paramagnetic compounds.

\section{References}

[1] C.Mandravel, A.M.Alstanei, V.Chiosa, Structura molecula- ra (Editura Universitatii Bucuresti, Bucuresti, 2001) 238pg .

[2] I.G.Murgulescu, V.E.Sahini, Introducere in chimia fizica, vol 1.2 (EdituraAcademiei 
RSR, Bucuresti, 1978) 500pg.

[3] R. Shida, Experimental Determinations of Magnetic Susceptibility and ofMaximum Magnetisation in Absolut Measure Proc.Roy.Soc, London.35 (1883) 404.

[4] B.N.Figgis and R.S.Nyholm A convenient solid for calibration of the Gouymagnetic susceptibility apparatus-J.Chem.Soc. (London) 4, (1958) 4190.

[5] VMincu Ph.D.Thesis (Universitatea Bucuresti, 1986) .

[6] V.Mincu, ESegal Proprietes magnetiques des combinai-sons complex des halogenures des metaux bivalents des com-poses pyridiniques (II), Rev.Roum. Chim.16 (1971) 1651.

[7] A.C.Banciu andVMincu, Electronic Spectra and Magnetic Susceptibility of Some Tetrahedral Chelate Complexes with Co (d7) and $N$ (sp2) bonds.Rev.Roum.Chim.25, 4 (1980) 513-20 citations ISI.

[8] V.Mincu, C.Lepadatu, M.Gutul, M.Brezeanu andM.Jitaru I.Optical and Magnetic Studies of Some Heteronuclear Com-plexes of Nickel and Zinc withHydrazine.Rev.Roum.Chim.27-8, (1982) 931-14 citations ISI.

[9] L. Dumitru L., Ph.D. Thesis (Universitatea Bucuresti, 2001).

[10] A.Soare and C.Mandravel A New Design for Crucial Experiment Installation Related to Magnetic Susceptibility Determination, Anal.Univ.Buc., an XVII, vol.II, (2008) 33.

[11] D.F. Evans Magnetic Susceptibility Determination for Paramagnetic Compounds in Solutions J.Chem.Soc. (London), (1959)
2003.

[12] C.Mandravel and V.Chiosa Metode de studiu ale struc-turii moleculare (EdituraUniversitatii Bucuresti, 2005) 257pg. [13] D.F. Evans A NewType of Balance for Magnetic SusceptibilityDetermination J.Phys.E, Sci.Instr.7 (1974) 247.

[14] L.Mc Mills, F.Nyasula and R.Barlog Magnetic Suscep-tibility of Coordination Compounds in the General Chemis-try Labortory J.Chem.Educ. 2 (2) 11-14, 2014

[15] T.Ikeda andH.Yoshaka New Method for Determinig Magnetic Susceptibility J Phys.Chem., 72, 13, (1968) 4392.

[16] J.F. Schenk The Role of Magnetic Susceptibility in Magnetic Rezonance Imaging: MRI Compatibility of the First and Second Kind Int.J.Medical Phys.23 (1993) 815.

[17] G.A. Bain and J.F.Berry $A n$ UpdatedTabulation of $\chi$ Values.J.Chem.Educ.85, (2008) 532.

[18] http: //www.history of magnetic susceptibility determinations/Gouy method.

[19] A.B.Ford, R.M.Senterfit and V.J.Flanigan Magnetic susceptibility and density determination for plutonic and metamorphic rocks of the Glacier Peak Wilderness and vicinity, Northen Cascades, Washington (U.S.Geological Survey Books, Washington, 1988 ) -file report 87-77.

[20] M.C.Wepler, J.Leopold, L.Dragonu, D.von Eloerfeldt, M.Zaitev and U.Wallzabe Magnetic properties of materials for $M R$ engineering micro-MR and beyond, Journal Magnetic Rezonance, 242, (2014) 233 